\title{
IMPACT OF WORK LIFE BALANCE ON EMPLOYEE PERFORMANCE WITH REFERENCE TO APPAREL COMPANY INSRI LANKA
}

\author{
Peiris M.K.S. \& Kennedy F.B. \\ Department of Management, Faculty of Commerce and Management, \\ Eastern University, Sri Lanka \\ kanishkasandsuni94@gmail.com\&kennedyb@esn.ac.lk
}

\section{ABSTRACT}

Work Life Balance (WLB) is such change introduced in the organizations. As a significant contribution to an organization success, flexible working arrangement (FWA), employee assistance programs (EAP) and Leave of WLBPs have emerged as significant antecedents of employee performance. The main purpose of this paper is to investigate the impact of work life balance on employee performance with reference to Apparel Company in Sri Lanka.A survey was carried out among executive and nonexecutive employees who are work in Selected Apparel Company in Sri Lanka. Selected 351 executive and non - executive employees who are working in MAS Active Trading Linea Intimo (pot) Ltd - Biyagama BOI zone. The findings indicated that the flexible working arrangement, employee assistance programs and leave are in high level in MAS Active Trading Linea Intimo (pot) Ltd. And also the results showed that leave have strong positive relationship with employee performance while flexible working arrangement and employee assistance programs have moderate positive significant relationship with employee performance. Altogether work life balance strong positively influence on employee performance.

Keywords:work life balance, work life balance practices, flexible working arrangement, employee assistance programs, employee performance

\section{INTRODUCTION}

In labour market, many changes have been occurred recently. Therefore, every organization makes adaptations to those changes and change their business processes accordingly. This is a new trend or a new challenge for the working environment. Work Life Balance (WLB) is such change introduced in the organizations. In a competitive working environment, many employees face some difficulties to balance their work and family life. Through this research, focus about how work life balance practices impact to employees' job performance. Employee performance is the achievement of a person in a particular field of expertise, in performing his or her job duties as delegated by superiors effectively and efficiently; thus, the ability of a person to perform on his or her job in order to reach the goals set earlier (Nawawi, 2009). In 21 ${ }^{\text {st }}$ century, workers' faced a major problem in balancing their own personal activities, family works and careers. They have huge responsibilities on their jobs as well as in their families. Therefore, imbalance in the work and family life leads negative outcomes to the society and organization. Some of negative impacts are; increase absenteeism, increase turnover, increase stress, low productivity, low level of motivation, Increase grievance and poor commitment and involvement. 
